\title{
Effect of citric acid on toxicity of graphene towards freshwater algae (Chlorella pyrenoidosa)
}

\author{
Chuntong Guo, Pingping Song, Xuesong Cao* \\ College of Environmental Science and Engineering, Ocean University of China, Qingdao 266100, \\ China \\ *caoxuesong521123@126.com
}

Keywords: graphene, citric acid, algae, toxicity

\begin{abstract}
With the increasing in production and application, graphene will inevitable be released into the aquatic environment and have impacts on aquatic organisms. In this work, we investigated the toxicity of graphene to algal cells (Chlorella pyrenoidosa) in the presence of dissolved organic matter. The results showed that the toxicity of graphene is concentration dependent, and the median effective concentration $\left(\mathrm{EC}_{50}\right)$ at $96 \mathrm{~h}$ was $41.35 \mathrm{mg} / \mathrm{L}$. In addition, the toxicity was significantly reduced by citric acid (CA), as a type of dissolved organic matter. The alleviated toxicity of CA was concentration dependent. This finding could provide useful data for assessing the environmental risk of graphene.
\end{abstract}

\section{Introduction}

Graphene is a kind of novel carbon material with $\mathrm{sp}^{2}$-hybridized single-atom-layer structure. It is a two-dimensional material composed of carbon atoms which are densely arranged like a honeycomb [1]. Graphene is considered to be composed of benzene rings, on which hydrogen atoms are removed [2]. It shows great mechanical stiffness, electronic transport capacity and excellent thermal conductivity due to its perfect structure [3]. Thus, graphene materials are applied in many areas, such as biosensors, drug delivery, adsorbent of enzyme, cell imaging and so on [4]. It has been proved that graphene materials are toxic to bacteria [5], plant cells [6], animal cells [7] and even human cells [8]. On the one hand, it brings convenience for people and promotes the progress of the society. On the other hand, it could inevitably be released into the environment, thus generating a negative effect [9]. Critic acid (CA), as a typical kind of dissolved organic matter (DOM), exists widely in the aquatic environment [10]. It is an important component in aquatic environment, which may interact with graphene in the water. Both DOM and nano-materials are present in aquatic environment. DOM may alter the behavior and fate of nanometer-materials in the water [11]. So far, there are a few of researches on the effects of DOM on organism toxicity of carbon nano-materials. Zhou et al. (2015) showed that the toxicity of graphene oxide (GO) to zebrafish embryos could be reduced by humic acid (HA) [12]. Lin et al. (2015) proved that toxicity of carbon nanotubes to algal cells was enhanced in the presence of SDBS and TX100; however, HA made the toxicity of carbon nanotubes diminished [13]. The purpose of this study is to explore the effect of citric acid on toxicity of graphene to freshwater algae (Chlorella pyrenoidosa). The outcomes will shed new light on ecological toxicity assessments of graphene nanomaterials.

\section{Materials and methods}

\section{Preparation and characterization of graphene}

Graphene was bought from Graphene Supermarket in USA. Citric acid was purchased from Sigma-Aldrich, USA. The morphological structure of graphene was observed under the transmission electron microscope (TEM) and scanning electron microscopy (SEM). Before the observation, $5 \mathrm{mg}$ graphene was added into $100 \mathrm{ml}$ anhydrous ethanol and was bath sonicated $\left(100 \mathrm{~W}, 40 \mathrm{kHz}, 25^{\circ} \mathrm{C}\right)$ for 60 min. TEM (H - 7650, Hitachi, Japan) was used to scan the size of sample. Tweezers were used 
to take a small amount of graphene on the mica sheet, and the sample could be scanned under SEM (S-4800, Hitachi, Japan) to determine the surface morphological structure of graphene.

\section{Cultivation of algal cells and toxicity test}

Chlorella pyrenoidesa was obtained from Institute of Hydrobiology, Chinese Academy of Sciences in Wuhan, China. It was cultivated in the 1/10 SE culture medium. The blood count plate is used to adjust the algal cells to the same level. Graphene in the concentration of $500 \mathrm{mg} / \mathrm{L}$ was prepared and was added into the algal cells cultivated for $24 \mathrm{~h}$. It was made to be $0,5,10,20,30,50$, $70,100,150,200 \mathrm{mg} / \mathrm{L}$ respectively. To explore the role of the DOM, CA (5, 10, $20 \mathrm{mg} / \mathrm{L})$ was joined in the algal cells treated by graphene as a comparison. Blank control was set. Blood count sheet was used to count the algal cells after $96 \mathrm{~h}$.

\section{Statistical analysis}

DPS 7.05 statistical software was used for statistical analyses, and each treatment was performed in triplicate. Single factor analysis of variance (ANOVA) with LSD test was used to analyze the significance level at $p<0.05$. Data are presented in the way of means \pm standard deviation (SD).

\section{Results and discussions}

\section{Characterization of graphene}

Scanning electron microscope (SEM) and transmission electron microscope (TEM JEM-2100, Japan) were used to test basic properties of graphene. TEM image (Figure 1A) shows that the size of graphene sheet is approximately $2.0 \times 3.5 \mu \mathrm{m}$. The sharp edges of graphene are evident, and the shape is irregular, folding, with high transparency. SEM image (Figure 1B) reveals that graphene surface is observed to be uneven.
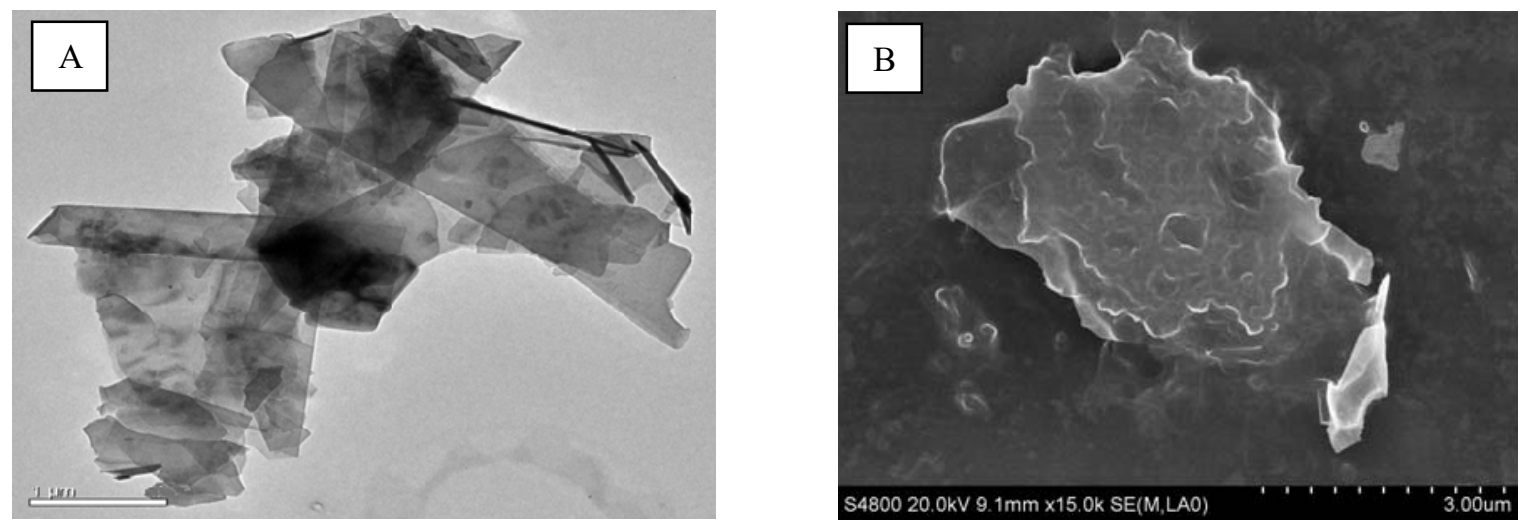

Figure 1. Characterization of graphene using TEM (A) and SEM (B).

\section{Toxicity of graphene to algal cells}

Figure 2 revealed that survival rates of cells decrease with the increasing of graphene concentration. Median effective concentration $\left(\mathrm{EC}_{50}\right)$ was $41.35 \mathrm{mg} / \mathrm{L}$ after calculated. So $40 \mathrm{mg} / \mathrm{L}$ of graphene was used to subsequent experiments.

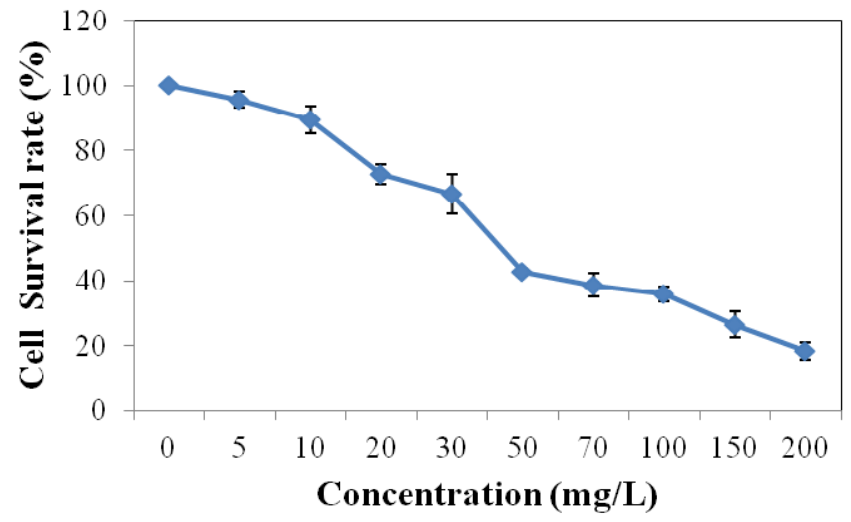

Figure 2. The cells survival rates of algal cells after exposed to different concentrations of graphene for $96 \mathrm{~h}$. 


\section{Toxicity induced by graphene in the presence of $\mathrm{CA}$}

CA solutions $(5,10,20 \mathrm{mg} / \mathrm{L})$ were added into algal cells with the treatment of $40 \mathrm{mg} / \mathrm{L}$ graphene. Figure 3 showed that graphene inhibited the growth of algal cells. However, the cell survival rate induced by graphene is increased in the presence of CA. With the increase of CA concentration, the toxicity reduced. When the concentration of CA is $20 \mathrm{mg} / \mathrm{L}$, cell survival rate reaches to $78.44 \%$, which is $37.07 \%$ beyond the group treated with graphene $(40 \mathrm{mg} / \mathrm{L})$ alone. This revealed that CA could reduce toxicity of graphene.

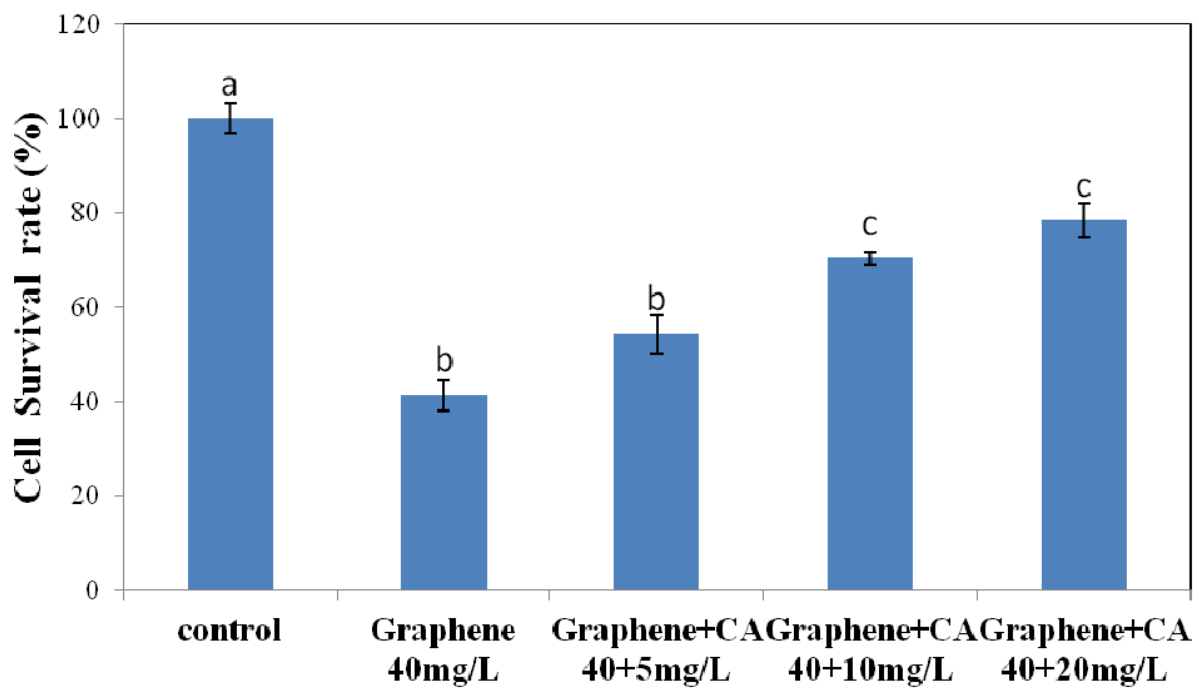

Figure 3. Cell survival rate of algal cells treated with graphene $(40 \mathrm{mg} / \mathrm{L})$ in the presence of CA $(5,10$, $20 \mathrm{mg} / \mathrm{L})$.

\section{Conclusions}

Graphene is toxic to algal cells and the median effective concentration $\left(\mathrm{EC}_{50}\right)$ is $41.35 \mathrm{mg} / \mathrm{L}$. As a type of dissolved organic matter, CA can reduce the toxicity of graphene to algal cells. The reduction in inhibition of algal growth was increased with increasing CA concentrations.

\section{References}

[1] Ying W, Yuyan S, Matson D W, et al. Nitrogen-doped graphene and its application in electrochemical biosensing. Acs Nano, 2010, 4(4):1790-8.

[2] Castro Neto A H. Drawing Conclusions from Graphene.// 2007 New England Section of the APS and AAPT Joint Fall Meeting. American Physical Society, 2007:33-37.

[3] Novoselov K S, Geim A K, Morozov S V, et al. Two-dimensional gas of massless Dirac fermions in graphene. Nature, 2005, 438(7065):197-200.

[4] Wang G, Qian F, Saltikov C W, et al. Microbial reduction of graphene oxide by Shewanella. Nano Research, 2011, 4(6):563-570.

[5] Omid A, Elham G. Toxicity of graphene and graphene oxide nanowalls against bacteria. Acs Nano, 2010, 4(10):5731-6.Seabra A B, Paula A J, Renata D L, et al. Nanotoxicity of graphene and graphene oxide. Chemical Research in Toxicology, 2014, 27(2):159-168.

[6] $\mathrm{Hu} \mathrm{X}, \mathrm{Lu} \mathrm{K}, \mathrm{Mu} \mathrm{L}$, et al. Interactions between graphene oxide and plant cells: Regulation of cell morphology, uptake, organelle damage, oxidative effects and metabolic disorders. Carbon, 2014, 80: 665-676.

[7] Zhang X, Yin J, Peng C, et al. Distribution and biocompatibility studies of graphene oxide in mice after intravenous administration. Carbon, 2011, 49(3):986-995. 
[8] Shaobin L, Tingying Helen Z, Mario H, et al. Antibacterial activity of graphite, graphite oxide, graphene oxide, and reduced graphene oxide: membrane and oxidative stress. Acs Nano, 2011, 5(9):6971-80.

[9] Nguyen-Phan T D, Pham V H, Shin E W, et al. The role of graphene oxide content on the adsorption-enhanced photocatalysis of titanium dioxide/graphene oxide composites. Chemical Engineering Journal, 2011, 170(1): 226-232.

[10] Quigg A, Chin W C, Chen C S, et al. Direct and Indirect Toxic Effects of Engineered Nanoparticles on Algae: Role of Natural Organic Matter. Acs Sustainable Chem Eng, 2013, 1(7):686-702.

[11] Jian Z, Zhenyu W, White J C, et al. Graphene in the Aquatic Environment: Adsorption, Dispersion, Toxicity and Transformation. Environmental Science \& Technology, 2014, 48(17):9995-10009.

[12] Yuming C, Chaoxiu R, Shaohu O, et al. Mitigation in Multiple Effects of Graphene Oxide Toxicity in Zebrafish Embryogenesis Driven by Humic Acid. Environmental Science \& Technology, 2015, 49(16).

[13] Zhang L, Lei C, Chen J, et al. Effect of natural and synthetic surface coatings on the toxicity of multiwalled carbon nanotubes toward green algae. Carbon, 2015, 83:198-207. 